Passing a catheter is often of advantage; and expulsion from the vagina may be effected if a light anaesthetic is given. In normal cases it is not necessary to massage the abdomen in the third stage. Massage often causes irregular contractions and retention. It is unnecessary to explore the uterus for retained membranes; they will probably come away as involution proceeds. If the membranes do not come away naturally in a day or two and give rise to local sepsis a glycerin drain may be advisable. When the placenta reaches the vulva the hand should not touch the abdomen, as it may produce constriction of the cervix, which would prevent expulsion of the membranes. Injection of saline solution into the umbilicus in some cases effects delivery of the placenta.

Manual removal of the placenta should be avoided, except for haemorrhage or complete retention, as it is not infrequently followed by some degree of pyrexia.

\section{Puerperal Sepsis}

There is no time to do more than mention this subject. With improved methods of treatment, as, for example, with prontosil in cases of acute blood infections, surgical intervention has been much diminished. Hysterectomy has always seemed to me a mistaken method of treatment, and has been responsible no doubt for the loss of some lives. Drainage of the abdominal cavity does not seem to me a rational method in these cases, as the infection is not comparable with that of appendicular abscess or pyosalpinx. I have found serum of value in some cases; and of course fresh air, colon lavage, and blood transfusion all help towards a cure.

In local or uterine sepsis glycerin drainage is the best method of treatment.

In cases of septic abortion it is advisable not to remove the ovum or placenta when first seen, but to delay until the patient's resistance has been improved with prontosil, etc. A glycerin drain may effect the spontaneous expulsion of the ovum. If not, removal of the uterine contents by the finger or forceps is not accompanied by much risk of disseminating the organisms by breaking down the barrier in the uterine wall. A mole which gives rise to haemorrhage should, of course, be removed as soon as possible.

In conclusion, we must remember that although we are often tempted to use surgical methods in obstetrical practice time and patience will do much to banish the possible complications which we apprehend. The results of operation at the moment may be dramatic, but the dice are loaded sometimes against us in the form of shock to the patient, haemorrhage, and sepsis. Masterly inactivity may seem to many to be poor treatment, but the results will often be infinitely better than those attained by surgical intervention.

A. Alfano (Rinasc. med., January 31,1937 , p. 47) states that recent studies of the extra-articular manifestations of acute articular rheumatism have induced him to record the following case. The patient was a girl aged 13, who was suddenly seized with abdominal pain, chiefly localized in the right side, constipation, vomiting, and fever. The pain in the lumbar region which subsequently developed made it doubtful as to whether the condition was a retrocolic appendicitis or suppurative peritonitis. The subsequent course of the disease made the last diagnosis appear the most probable at first, but later the occurrence of pain in the typical situation showed the true nature of the disease.

\section{AN UNUSUAL CASE OF HERMAPHRO- DITISM}

\author{
BY \\ HAROLD CHAPPLE, M.Ch., F.RC.S. \\ Senior Gynaecologist to Guy's Hospital
}

I put forward the details of this case as of considerable importance in having a direct bearing on the probiems of sex, its origin, and manifestations.

\section{Case Report}

The patient consulted me when she was 18 years of age because she had never menstruated, though she had had frequent manifestations of sexual excitement at irregular intervals, and had become anxious as to their exact significance. Her general bearing was that of an attractive female, aware of her beauty, both of face and figure. Her voice was pitched in the female register.

On examination she was found to be a beautiful woman, remarkably well developed as far as her typically female body was concerned. The face was free from hair. Her breasts were large and full, her pubis covered with a mat of hair, Her pelvis was rounded and well developed. Her clitoris, which bore to the naked eye a strong resemblance to a small penis not fused on its ventral aspect, was conspicuous between her labia, which were fully developed and definitely larger than the average. The vagina was about one and a half inches in length and terminated in a smooth, rounded extremity, but on removal of the examining finger it collapsed so as not to seem so long as the finger had indicated. She was very active sexually, and had a lover who had frequent connexions with her, and during these she became very excited. This man, an experienced bachelor, had assured her that he was able to complete the act with great satisfaction in spite of the shortness of her vagina, and that he had never had relations with such a passionate woman. These facts are mentioned to show that she was very highly sexed. Her sexual desires were invariably directed to males; indeed, she said she had rather an antipathy to females.

Desiring to settle in life and to cease her irregular friendships with her various lovers, she consulted me again in 1921 with the object of having her " passage" elongated, and asked if it were possible to make an artificial uterus so that she might have children. On examination I could not detect any sign of the presence of a uterus. I found in each inguinal canal a smooth, rounded lump which was readily returned into the abdominal cavity by slight pressure, but appeared again when the pressure was removed. She complained that squeezing the lump caused a pain, which she herself described as sickening. I explained to her that it was possible to make an artificial "passage" for the sake of intercourse, but that it was not possible to construct a uterus from which she could bear children. I added that there was a definite risk to her life in the former procedure if carried out by the abdominal route, and she wisely decided not to undergo it. Noting the elasticity of the perineal tissue, an elastic T-bandage was devised which kept up a constant pressure on a metal dilator. This was worn during sleep and for as long a part of the day as possible. Rapidly it became possible to increase the size and length of the dilator, and the patient's persistence was rewarded by the development of a passage three inches in length which on superficial examination bore a strong resemblance to the lower end of a normal vagina.

\section{OPERATIONS}

Three years later she came to see me again because the lump in the right groin had become painful and had increased in size, and an operation for the cure of an inguinal hernia was undertaken. The lump was exposed and was manifestly a small testicle, complete in every detail, except that no vas could be found. It was replaced in the abdominal cavity and the canal closed. Two years later a similar operation 
for the same reasons was performed on the left side, when, as on the previous occasion, what appeared to be an undoubted testicle was replaced in the abdominal cavity. Four years later the hernia on the right side caused her much pain and she said the lump was trying to reappear; this time she insisted on its removal. This was carried out, and the appearance of the lump at the previous operation was confirmed ; it turned out to be a definite testicle complete in every detail. After its removal her sexual ardour was considerably lessened, but remained identical in its direction.

The specimen was examined after removal by Dr. Nicholson, professor of morbid histology at Guy's Hospital, and his report is appended:

"The specimen was instantly identifiable with the naked eye as a testis and epididymis. The former measured $3 \mathrm{~cm}$. in length, $2.4 \mathrm{~cm}$. in breadth, and $2 \mathrm{~cm}$. in depth, and was covered externally by peritoneum. On section it was pinkish in colour and studded everywhere with minute granules, slightly raised above the surface. The upper pole passed gradually into the thickened head of the epididymis. Elsewhere it was surrounded by a dense tunica albuginea. The epididymis consisted of fibrous and adinose tissue with numerous small lumina.

"On microscopical examination the testis presented the typical appearance of the atrophied organ (see figure).

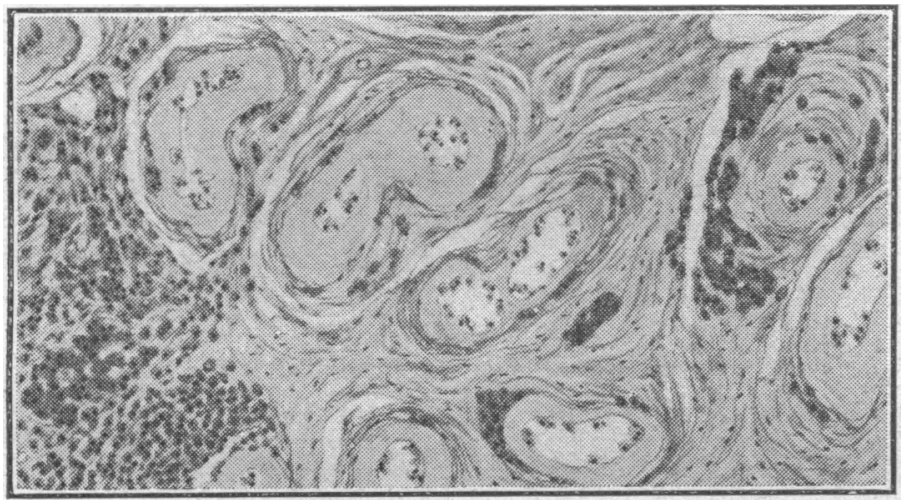

"The spermatic tubules were thick and consisted of a broad hyaline basement membrane surrounding a lumen in which a few degenerate cells of irregular shape were present. There were no signs whatever of spermatogenesis. The intratubular stroma was dense and non-cellular, but contained large numbers of big, intensely eosinophil interstitial cells, solitary and in groups. They often formed incomplete envelopes around the tubules, or were aggregated into definite nodules, or adenomata, the largest of which measured 1 to $2 \mathrm{~cm}$. in diameter. The tubules of the epididymis were lined witi columnar epithelium, on which cilia were visible. Their lumina were always empty. They were surrounded by thick fibromuscular envelopes. The vessels of the pampiniform plexus were numerous, and all their coats, more especially the media, were sclerosed. The vas deferens was not identified."

On the three occasions when the patient was anaesthetized I had taken the opportunity for a thorough examination of the pelvis, and there was no sign of any structures in the pelvic cavity which might indicate the presence of ovaries.

This case appears to me to be of great interest from several points of view. Here we have a beautiful fully developed woman, with all the physical characteristics of the so-called female, and yet she has no ovarian secretion or uterus-nor has she ever had. Clinical observation of human beings shows of course that the original division into male and female is in reality a very superficial one, and can only be maintained on the anatomical ground of the gross appearance of the external sex organs. Certain physical and mental characteristics are generally accepted as appertaining to the males and females of the species, and it is a platitude to observe that there are very few pure males or females in the human species, but' that the vast majority of individuals are a mixture in varying proportions of the male and female elements. Their characteristics are usually considered to be due to the secretions of the gonads. The present case directly negatives this supposition, and proves that we must look further back for their origin. This woman had never possessed ovarian tissue at all: indeed, she had testicles.

\section{Factors that Determine Sex}

The origins of all the ultimate characteristics of the future individual are contained, of course, in the original fertilized and developing ovum, and must be derived from the original spermatozoon and ovum, which contain the factors that determine the particular type and its. sex. This case shows that these factors must be independent of the gonads. Indeed the factors that determine the type of the several characteristics of a particular individual must determine also the type of the gonads that will be present in that individual.

The type of each individual is developed with the gonads and not because of them, the gonads being just one of the elements in the structure of the individual and not, as was supposed, the structures that determined the characteristics. Thus an individual may be physically very feminine, mentally a mixture of male and female, and yet have testicles or any variety of the male or female organs. The truth of this has appeared obvious to me for many years, but I have not been able to demonstrate it completely before, although it was suggested by a mass of evidence from clinical observations. The degree of development of the external sex organs varies greatly in each individual. In many females the clitoris and labia approximate quite closely in appearance to a penis and a scrotum, not of course fused in the midline. The degree of development of the male organs varies too, but what is more important to observe is that the sexual characteristics associated with these developments are just as variable, and are not commensurate with the degree or type of anatomical development. For example, great physical development is not necessarily associated with great sexual ability or desire, nor is great physical beauty necessarily associated with great sexual attraction or small anatomical development of the sex organs. This is equally true of the mental characteristics of the individual in relation to the degree of development of the sex organs and the type of gonads, the anatomical, mental, and sexual characteristics of each individual being very largely independent of one another. Indeed it appears to me simple to deduce that the superior intelligence of the female is the result of her physical disadvantages.

The value of the ovarian secretions is, then, much more superficial than is usually supposed, and this is of great interest in view of the attention drawn to them by recent work. The missing secretions in any particular individual can be augmented by the administration of artificial substitutes and important superficial changes be thereby produced, but the type of the individual is not altered. Also the ovaries have been removed surgically in a large number of women without making a radical change in the "type," though in a proportion of cases certain symptoms will follow, and some of these may attract a great deal of attention.

\section{Sex Problems}

Clinical observations have confirmed me in the belief that the pure male type and the pure female type are seldom satisfactory, the former generally being lacking 
in real intelligence and the latter in physical power. The best human beings are those in whom there is a considerable admixture of the characteristics of both sexes, with an interplay of the elements, and it appears to me that for a man to be what is commonly known as " successful". he must possess a considerable amount of the mental attributes of the female, and the ." successful " female must possess a considerable amount of the physical attributes of the male. The so-called "war of the sexes" is therefore about as absurd as any other war, and the question as to who fights whom, and on which side, must often be difficult to answer.

Of late years sex problems have been more openly discussed, and certain advantages have accrued from this. On the other hand types of sexual activities between persons of the same sex have been dragged into the light from the relative obscurity that previously had partially concealed them, and at times even have been exalted by certain authors to such an extent as to become a menace to society, a great deal of harm resulting. The position regarding them therefore needs some clarification. There are individuals with certain male externals who have an excessive amount of the female in them, and females with very obviously excessive amounts of the male apparent in their appearance, movements, and general mannerisms. Some of these indulge in sexual perversions, and the natural resentment that is felt against these activities is often toned down by the illusion that this is a glandular problem and so calls for sympathy and not drastic opposition. No one would justify excessive violent attacks by a male on a female because of the activity of the secretions of his sex glands. Again, it is true that the aggressive sexual female has often a great deal of the male in her, but this is not regarded as a justification for gross sexual activities on her part. The case to which I have referred in detail shows that it is possible for an individual to have a very considerable mix-up of elements and yet confine "her" sexual activities entirely and successfully to the "opposite" sex.

The causative factors of homosexuality and Lesbianism are not to be found, therefore, so much in the secretions of the gonads as in the type of the individuals concerned. Their behaviour should not be regarded as justifiable on the ground of these glandular secretions, nor shou'd it be held that it is impossible for them to learn and cultivate an adequate control. In this matter the legal and medical professions are often found at variance and are often led away from the main issue, the former being more interested in upholding "the majesty of the law," and the latter in attempting to find a cause for the behaviour and to supply a suitable remedy. It is just as possible for the participants in these practices to learn control as it is possible to control any other bodily desires, normal or abnormal. It is vital that they should be made to realize that their practices are not excusable on the grounds of the secretions of the sex glands, as, failing this, they are dealt with drastically by the lawand justly so-for the obvious benefit of the herd-in which we live.

The December issue of Medical Life is an Army Medical Library number commemorating the centenary of the foundation of the Army Medical Library at Washington. In addition to other papers, it contains greetings from the Royal Society, the oration delivered on the occasion by Sir Humphry Rolleston (of which an abridged version appeared in our issue of November 28 , 1936), and a portrait of the late medical historian, Colonel Fielding Hudson Garrison.

\section{DERMATITIS ARTEFACTA : A NOTE ON AN UNUSUAL CASE}

BY

\author{
E. W. PROSSER THOMAS, M.A., M.D. \\ Registrar, Skin Department, St. Thomas's Hospital
}

The term "dermatitis artefacta" is reserved for those cutaneous lesions which are produced by the patients themselves with intent to deceive. It does not therefore include the group of self-inflicted dermatoses known as neurotic excoriations in which the patients neither intend nor practise deception but are the victims of an irresistible desire to pick, scratch, or otherwise injure the skin, nails, or hair (trichotillomania); this impulse in some instances may have originated in a pre-existing or existing true dermatosis, such as scabies or acne (Brocq's acne excoriée des jeunes filles). Such cases are quite distinct clinically and psychopathologically from the group of "feigned" eruptions to which the ensuing remarks are confined and of which the case reported is an example.

\section{Diagnosis}

Dermatitis artefacta is by no means a rare condition, but to anyone who has not previously encountered it the possibility that he is dealing with a self-produced dermatosis might not easily come to mind, and it is probable that a number of cases, especially of the milder type, are missed.

The diagnosis may be comparatively obvious or extremely difficult. The subjects may be men or women, but the great majority are women. They are usually young-between 15 and 25 years of age. There may be nothing in their past histories suggestive of any psychological abnormality, and they are not the type of person commonly called "nervous"; on the contrary, they often present a curiously unemotional, almost indifferent, attitude on examination, which is reflected in their facial expression to such a degree that their physiognomy, though difficult to describe, may be quite distinctive and of valuable help in diagnosis. This apathy, if it may be so called, is neither to their environment nor to their interrogator. They are often intelligent, perhaps above the average, and answer questions with apparent frankness, though they do not care to volunteer much information concerning themselves or their condition. Their apathy is only towards their disease, and in this direction their lack of interest is so unnatural as to be striking. They rarely complain, and may regard a number of heavily infected discharging lesions with what appears to be almost a complaisant and contented eye.

The lesions themselves present great variety in shaps, size, and character, as would be expected from their aetiology. They may be linear, striped, band-like, diskshaped, or have a fantastic outline. They are constant only in one particular - that they do not conform to the lesions of any recognized dermatosis. Their border is important; it is usually sharply defined, pointed, or angular, and may have a.thin line of erythema between it and the surrounding skin, which is probably quite healthy. If a liquid agent has been used there may be one or more drop-shaped or streak-shaped subsidiary lesions, caused by spilling or running. The location of the lesions is important. They naturally occur in places easily accessible to the hand: the left arm and side of the body are therefore favourite sites, but the face or neck, 